\title{
A Numerical Approach on Reduction of Young's Modulus during Deformation of Sheet Metals
}

\author{
Chetan Nikhare \\ Mechanical Engineering Department, University of New Hampshire, Durham, USA \\ Email: chetan.nikhare@gmail.com
}

Received November 23, 2011; revised December 25, 2011; accepted January 3, 2012

\begin{abstract}
The paper investigates the elastic behavior of the metal after unloading. For this purpose the strip of metal with tensile gauge length was simulated with high and low strength material. Further the channel forming was modeled for combination of materials to predict the spring-back and compared the results. It is observed that the Young's modulus (E-value) decreases with the increase in plastic strain. The strength of the material has no effect on the decrease in the E-value after unloading during tension test. However in channel forming the E-value after unloading depends on the starting E-value, spring-back angle and maximum strain achieved in the channel. The proposed mathematical equations to determine the E-value after unloading from the tension test and channel forming test gives very good prediction with each other. It is also found that the lowest spring-back occurred in the channel with the composite Hard-Soft material.
\end{abstract}

Keywords: Elasticity; Spring-Back; Channel Forming; Optimization; Deformation

\section{Introduction}

The shape change of the deformed component after unloading is called the elastic recovery. This behavior is been named as the spring-back in sheet metal stamping. The spring-back is defined in different words by many researchers. The geometrical change in the part after forming when the force from the forming tools was removed is denotes as spring-back [1]. This behavior is most common in sheet metal formed components in which the one or two dimensions are much larger than the other ones. [1] The dimensional inaccuracy in the stamped part is due to the spring-back. Some studies shows that the final shape of the parts depends on the amount of elastic energy stored in the part during the sheet metal forming process [2]. The amount of elastic energy stored is a function of many parameters thus spring-back prediction is a complicated task. The shape error due to the spring-back considers as the manufacturing defect in sheet metal forming process. Another definition of the spring-back is referred to as the undesirable change of part shape that occurs upon removal of constraints after forming [3]. It can be considered a dimensional change which happens during unloading, due to the occurrence of primarily elastic recovery of the part.

Spring-back depends on the amount of draw-in during deformation. More the draw-in, more dominant will be the spring-back. Other process parameters which tend to give more spring-back were larger corner radius of the die set and lower clamping force $[4,5]$. It has also inves- tigated that the spring-back also depends on the material and process parameters. The influencing parameters for the strong spring-back were in descending order: punch corner radius, die corner radius, blank holding force, supporting force and lubrication [6]. The study of springback behavior on ultra high strength steel sheet in bending was performed under controlled condition using $\mathrm{CNC}$ servo press. The spring-back amount measured for the steel sheets was almost proportional to the ratio of tensile strength to the elastic modulus. The spring-back was little sensitive to the forming speed and the holding time at the end of the process [7]. Spring-back is a common occurrence due to bending of the sheet during forming whereas curl was observed in the sheet due to material sliding over the die radius [8]. Curl is also the closest influential factor for spring-back. The non-linear relation predicted between curl height and the back tension [8]. This understanding and prediction would not be clear without the investigation of hardening models.

Some of the numerical studies tried to predict the spring-back behavior for experimental comparison and several work-hardening models were evaluated in order to determine their influence on the numerical prediction of the spring-back phenomenon [9]. Based on the set of experimental results the constitutive parameters identification was performed [10]. Generally the spring-back results showed the sensitivity on the work hardening models. Due to the high level of equivalent plastic strain achieved in the U-shape channel the differences in the 
amount of spring-back prediction was not higher [9]. However the differences found in the study [11,12] where the strain level was quite low compared to the previous mentioned literature. The study performed [9] on the work hardening models the differences exist with experimental comparison and were associated with the predicted through thickness stress levels. The accurate prediction of the spring-back through the numerical methods depends on the materials hardening rule $[4,5]$. The constitutive equation for stress-strain curve for non-linear combined hardening rule was proposed depend on the non-linear kinematic hardening theory of Lemaitre and Chaboche and Barlat89's yielding function. It was found that the isotropic hardening rule over predicts the springback behavior compared to the proposed model. It was also observed that Barlat89's and Hill48's yielding function gave the better co-relation with experiments than the von-Mises yielding function [13]. This tells that the spring-back was sensitive to the work-hardening model. In the forming of U-shape channel it was identified that the strain path changes and was associated with the bending-unbending of the channel during forming. It was also noted that the strain achieved in each strain path are equally important as the strain path changes during the forming [9]. It was also shown that one model predicted larger spring-back angles for some materials and smaller for other ones according to the predominant strain-paths and strain-path changes. The comparison on the influence of the work-hardening models on spring-back, different trends was expected depending on the selected sheet metal formed part as well as the process conditions [9]. The numerical prediction of the spring-back was strongly dependent on definition of the constitutive model for the sheet metal mechanical behaviour under the change in strain-path and the occurrence of the stress reversal during the bending to unbending transition on the die radius [14]. In addition the investigation on number of integration points through thickness has done by many researchers to understand the accuracy in prediction [1, 15-20]. Wagoner et al. [21] recommended the implementation of 25 to 51 IP for $1 \%$ accuracy in the prediction.

Previous studies performed on the influence of change in elasticity during plastic deformation noted quite interesting outcomes found that some simulation results was in low precision when compared to the experiments [22]. It was found that the E-value varies after plastic deformation [23-29]. Thus consideration of this change in E-value would be needed to improve the spring-back simulation. The decrease in E-value was experimentally shown and proposed the linear relation $[29,30]$ between E-value and the plastic strain. The analytical model developed with the consideration of change in E-value for the estimation of top roller position predicted larger spring-back compare to with the constant E-value [24].
Similar results achieved by $[26,27]$ for the U-channel and predicted closer results with experiments. The microscopic approach through nano-indentation on the individual phases showed decrease in E-value with plastic deformation. Some of the dislocation associated with the pile-up of dislocations near the grain boundary and was the influential factor for E-value change [28].

In this study the E-value change was investigated through the longitudinal tension test and channel forming model. The tensile gauge sample was deformed for different strain values and the E-value after unloading was predicted. Further the channel forming was studied for single material with different starting E-values. The equation for estimation of E-value after unloading was proposed for both longitudinal tension test and channel forming model. Both proposed equation were compared to find the discrepancy in the method. In addition the channel forming was used to understand the spring-back behaviour of the composite material. In this different starting E-value and strength level combination were simulated.

\section{Materials}

The materials investigated in this study are the two steel types for which the tensile true stress-strain curve is shown in Figure 1 and the mechanical properties are tabulated in Table 1.

Holloman's power law (Equation 1) was used to generate the true stress-strain curve shown in Figure 1.

$$
\sigma=K \varepsilon^{n}
$$

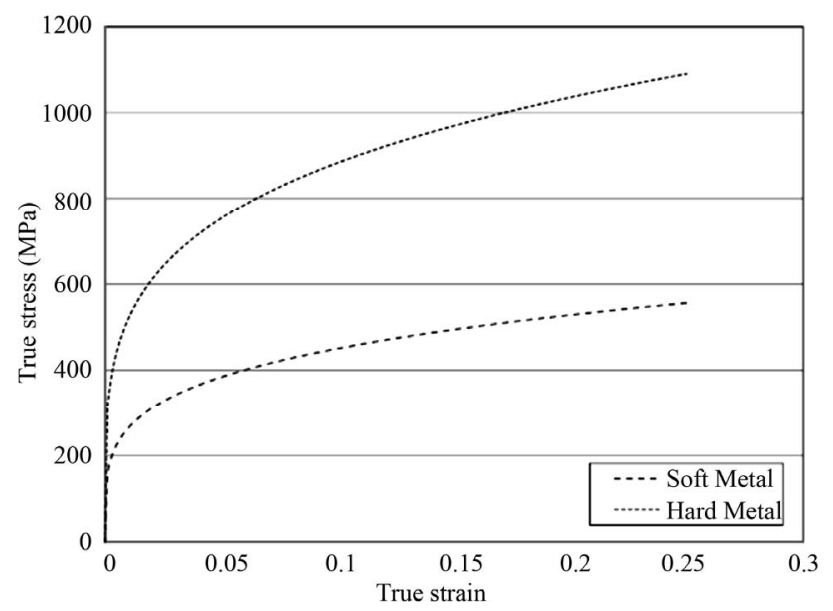

Figure 1. Tensile true stress-strain curve for two steel type materials.

Table 1. Mechanical properties for the two steel type materials.

\begin{tabular}{cccc}
\hline \multirow{2}{*}{ Material } & \multicolumn{3}{c}{ Mechanical Properties } \\
\cline { 2 - 4 } & YS (MPa) & $K(\mathrm{MPa})$ & $n$ \\
\hline Soft Metal & 183 & 765 & 0.23 \\
Hard Metal & 359 & 1500 & 0.23 \\
\hline
\end{tabular}




\section{Methodology}

The elastic behavior of the sample in tension loading and unloading at different strained condition was simulated with the longitudinal tension test (Figure 2). Further this behavior was predicted with the channel forming model (Figure 3). The spring-back occurred in each case was predicted and mathematical equations were determined. In addition the Taguchi method of $L_{9}$ array was performed to find out the most dominating factor on the spring-back behavior. Further the combinations of materials were simulated to understand the effect of different young's modulus value and different strength level.

\subsection{Longitudinal Tension Test}

The longitudinal test was modeled based on the tensile sample as recommended in Australian Standard AS 1391-1991 with only the consideration of gauge length of $50 \mathrm{~mm}$ and gauge width of $12.5 \mathrm{~mm}$ on specimens. The loading-unloading curve for 20 strain values was performed starting from $1 \%$ to $20 \%$ strain with the interval of $1 \%$ strain. In each case the unloading E-value was predicted. In some cases the thickness of the sample was divided into two sections for the application of different material properties in each section. Similar procedure was applied to understand the unloading behavior and the prediction of E-value.

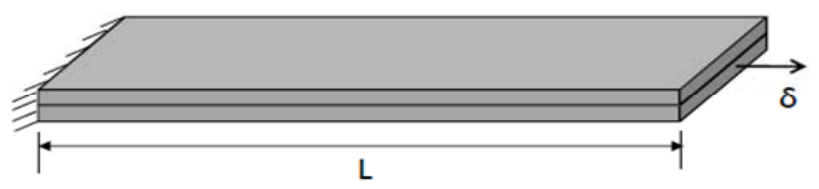

Figure 2. Longitudinal tension tests.

\subsection{Channel Forming}

The schematic view of the channel forming model is shown in Figure 3; was used to form the channels for spring-back effect. All essential tool dimensions are mentioned in the Figure 3. For all simulations the enough blank holder force was applied so that the blank can slide easily without any stretching. The blank was used with the length of $85.5 \mathrm{~mm}$ and thickness of $2 \mathrm{~mm}$. The punch depth of $40 \mathrm{~mm}$ was applied to all simulation except for the sensitivity analysis simulations.

\subsection{Numerical Method}

The longitudinal tension test and channel forming tests were investigated using ABAQUS/Standard 6.8-1. The three-dimensional model approach was used for the longitudinal tension test whereas the two-dimensional model was used to perform the channel forming test. In longitudinal tension test the reference point was used to apply the displacement for deformation. The reference point was constrained to one end of the sample with the help of coupling constraint. The other end of the tension sample was fixed. The tension sample was assumed as deformable body with C3D8R 8-node linear brick elements.

In channel forming model the tooling was assumed as rigid surfaces, while for blank deformable CPE4R 4-node bilinear plane strain elements were applied. Four layers through the material thickness were used and the maximum element size was chosen to be $0.5 \mathrm{~mm}$. In the model the interaction between the blank and the tooling was assumed with the coefficient of friction of 0.1 .

The material curve as shown in Figure 1 with isotropic plasticity was used in all the simulations. The spring- back measurement is shown in Figure 4.

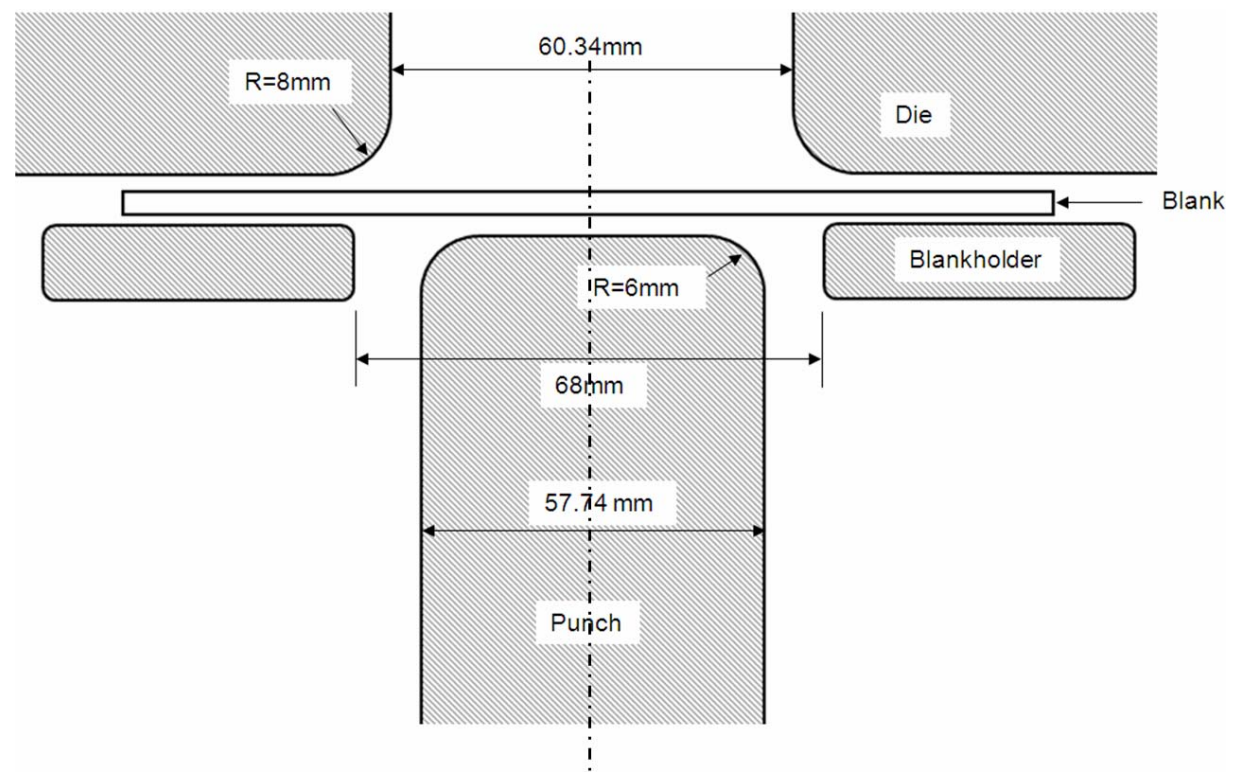

Figure 3. Channel forming model. 


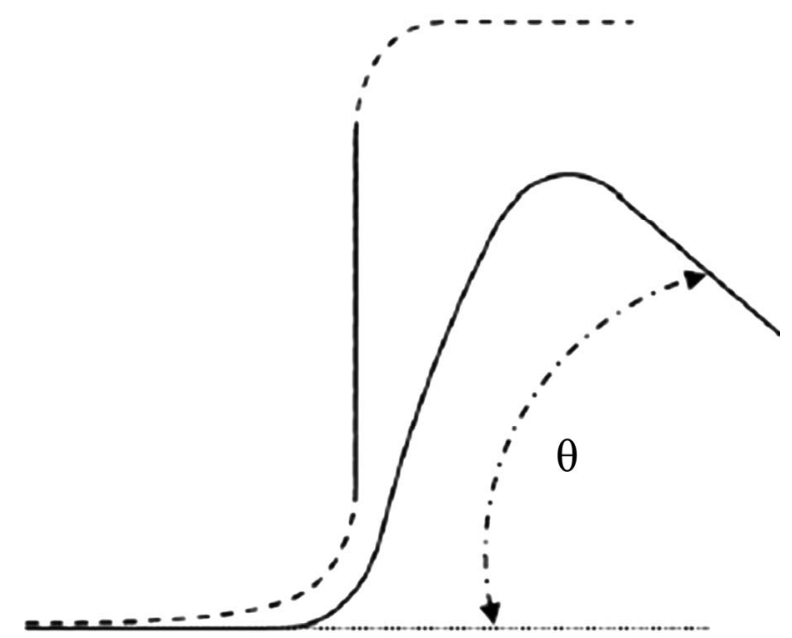

Figure 4. Spring-back measurement.

\subsection{Robust Design}

In this section, the Taguchi method was used with an orthogonal array of $L_{9}$ to analyse the effect of various material parameters on the spring-back. The quality characteristic measured was the spring-back for all the nine simulations (experiments) designed by the $L_{9}$ array. Since the objective is to minimise the spring-back, out of three signal-to-noise ratios [31] the "smaller the better" is the option for this study as the aim is to ascertain the minimum spring-back. The signal-to-noise ratio for "smaller the better" is given below:

$$
\eta=-10 \log \left(\theta^{2}\right)
$$

The important parameters (control factors) that were considered and included in the present analysis are:

1) $E_{B D}$

2) $\delta$

3) $K$

4) $n$

Table 2 lists the levels used for the above factors for channel forming. The chosen numerical values are not related to any material but comparable to real materials. The values chosen and set to generate the three levels at an interval to study the dominating factor which is responsible for higher springback from the considered four parameters.

The total number of degrees of freedom for the system is 9 (two for each of the four control factors and one for the overall mean). Hence an $L_{9}$ orthogonal array was chosen to design the simulation (experiments). The log sheet for the nine simulations (experiments) is given in Table 3.

\section{Results and Discussion}

The E-value after unloading at each plastic strain level is shown in Figure 5. It is found that the E-value decreases with respect to increase in plastic strain. Three different
Table 2. Control factors and their levels.

\begin{tabular}{cccc}
\hline orsFact & Level 1 & Level 2 & Level 3 \\
\hline$E_{B D}$ & 210 & 130 & 50 \\
$\delta$ & 40 & 30 & 20 \\
$K$ & 1500 & 1000 & 500 \\
$n$ & 0.25 & 0.15 & 0.05 \\
\hline
\end{tabular}

Table 3. Level of control factors for spring-back.

\begin{tabular}{cccccc}
\hline Expt. No. & $L_{9}$ Array & $E_{B D}$ & $\delta$ & $K$ & $n$ \\
\hline 1 & 1111 & 210 & 40 & 1500 & 0.25 \\
2 & 1222 & 210 & 30 & 1000 & 0.15 \\
3 & 1333 & 210 & 20 & 500 & 0.05 \\
4 & 2123 & 130 & 40 & 1000 & 0.05 \\
5 & 2231 & 130 & 30 & 500 & 0.25 \\
6 & 2312 & 130 & 20 & 1500 & 0.15 \\
7 & 3132 & 50 & 40 & 500 & 0.15 \\
8 & 3213 & 50 & 30 & 1500 & 0.05 \\
9 & 3321 & 50 & 20 & 1000 & 0.25 \\
\hline
\end{tabular}

starting E-values (210, 160 and $20 \mathrm{GPa})$ were modeled and E-value after unloading was measured for different level of plastic strain. Based on the curve shown in Figure 5, the Equation 3 was assumed and proposed to predict the E-value after unloading with the help of E-value before loading and the intended plastic strain value. The calculated E-values after unloading show very good agreement for all three different curves.

$$
E_{A D}=E_{B D}-1.5 E_{B D} \cdot \varepsilon
$$

The spring-back after unloading in channel forming for 20 different starting E-values $(210,200$ till 20) is shown in Figure 6. The interesting fact is observed that with the lower starting E-value the curl is more dominant. Thus it can be noted that for the same strength level the steel will have significantly lower curl than the aluminum and magnesium due to difference in E-value.

The achieved plastic strain after forming and before spring-back for the maximum strain region (region indicated by square in the inset of Figure 7) is plotted along the position of elements in the channel (Figure 7). For same strength level with higher starting E-value the maximum plastic strain is achieved; whereas for lower starting E-value the strain value is comparatively very low. Thus the fact is interesting that the starting E-value affects the strain level during forming.

The plot of spring-back angle with respect to the achieved maximum plastic strain for each starting Evalue is shown in Figure 8. The linear relationship is observed and given in the Equation 4.

$$
\theta=-1280 \cdot \varepsilon+156
$$




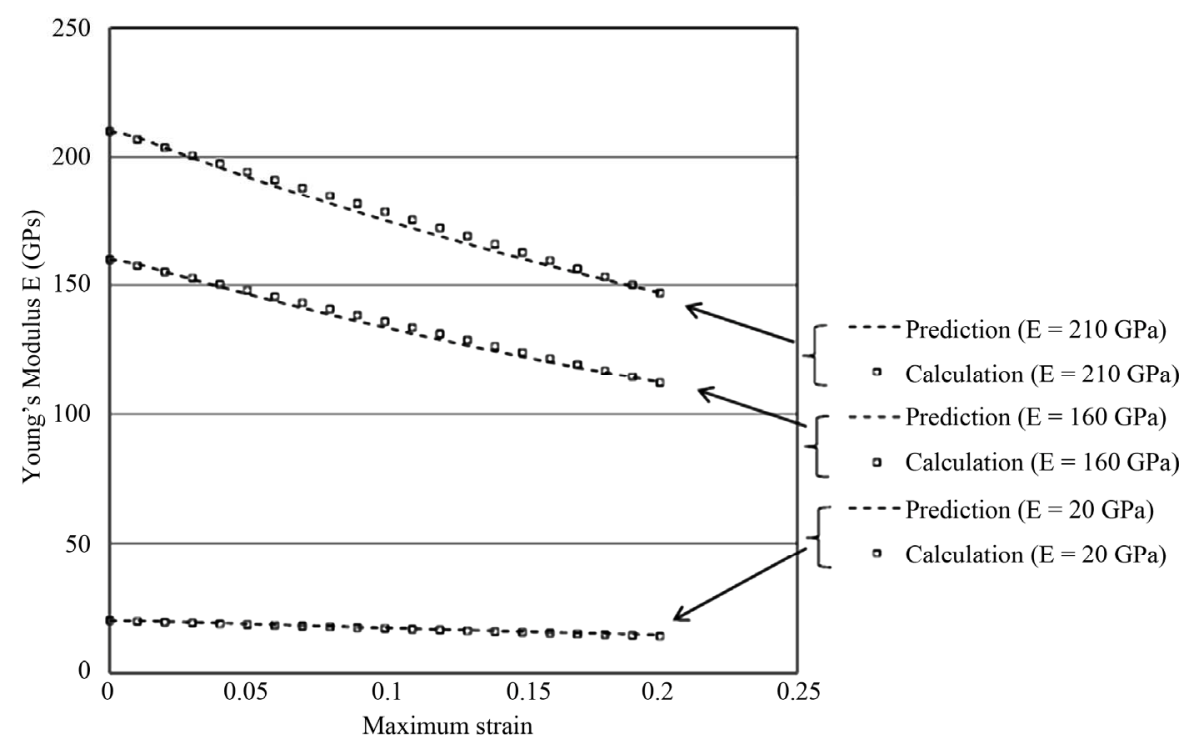

Figure 5. E-value after unloading at different plastic strain.

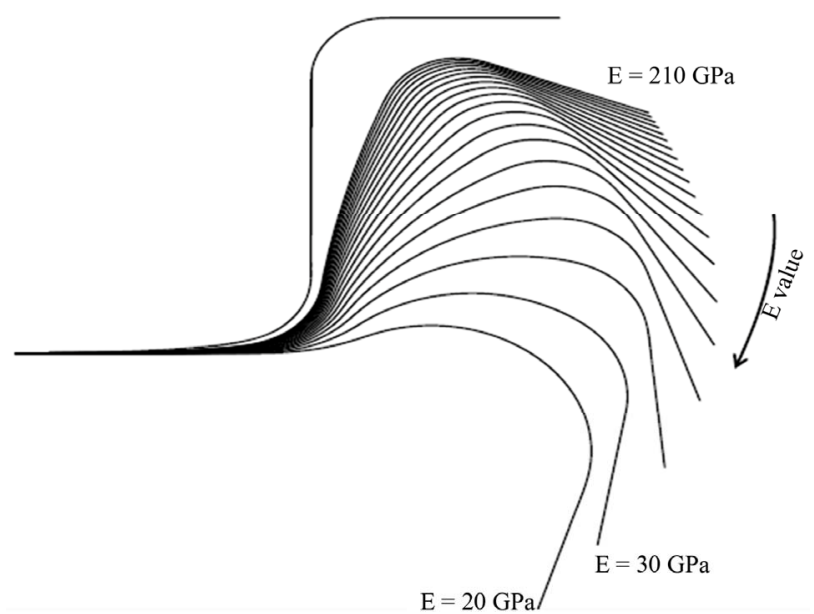

Figure 6. Spring-back for different value of initial starting Evalue.

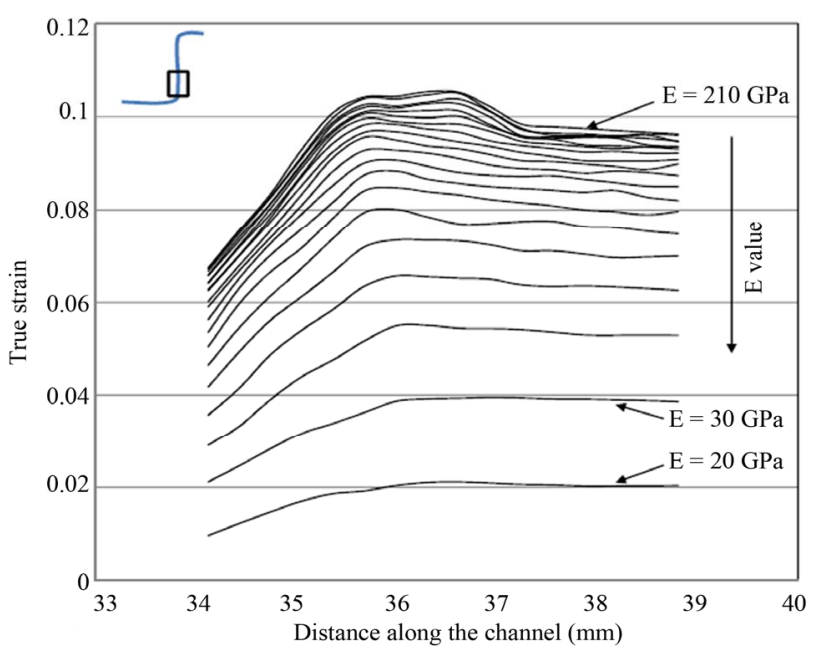

Figure 7. True plastic strain along the channel for a small section.

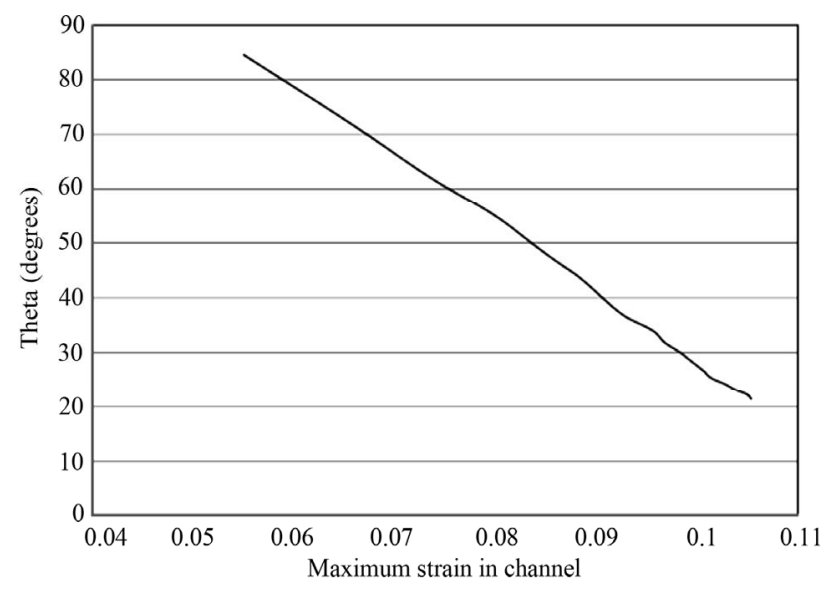

Figure 8. Spring-back angle for different starting E-value with respect to the maximum plastic strain.

The non-linear relation is observed in between the E-value and the spring-back angle (Figure 9). The relationship is given in Equation 5. The modified proposed relationship based on trial and error method understanding and is given in Equation 6 which depends on the E-value after unloading, spring-back angle and maximum strain achieved before spring-back. Similarly the nonlinear relation between the E-value after unloading and the maximum plastic strain achieved before unloading is shown in Figure 10.

$$
\begin{aligned}
& E_{A D}=5502 \cdot \theta^{-1.126} \\
& E_{A D}=1.2 \cdot E_{B D} \cdot \theta^{-\varepsilon}
\end{aligned}
$$

\subsection{Sensitivity Analysis}

The percentage effect of different material parameters are analysed by performing the nine simulations. The desired 
and the final profile with spring-back for all 9 simulations are shown in Figure 11. The spring-back angle is predicted in all nine simulations and tabulated in Table 4.

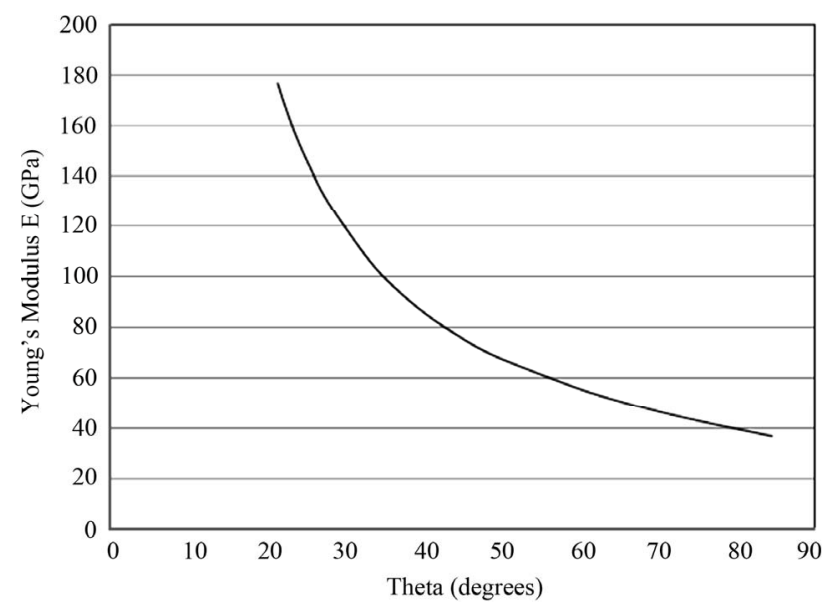

Figure 9. E-value after unloading for their respective springback angle.
Here the third setting shows least spring-back as compared to others. This may be due to less punch displacement and softer material.

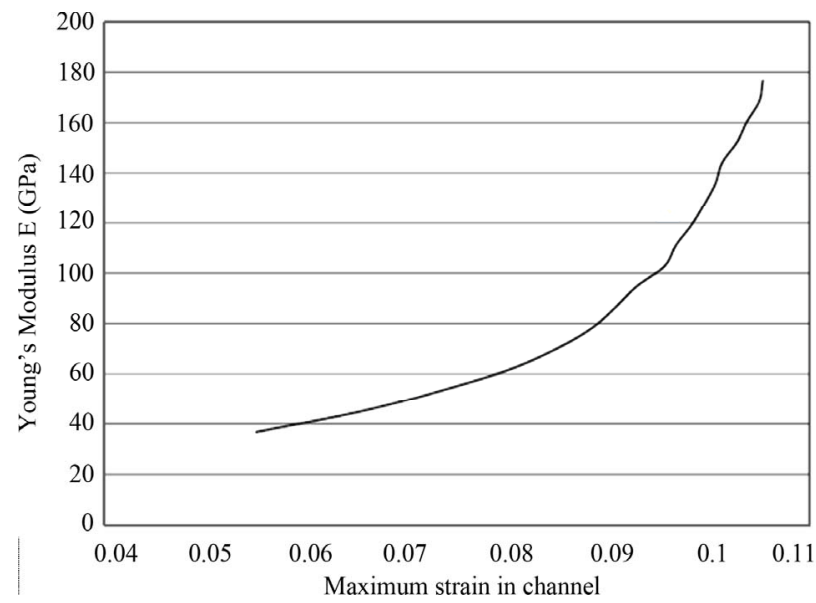

Figure 10. E-value after unloading for their respective maximum plastic strain.

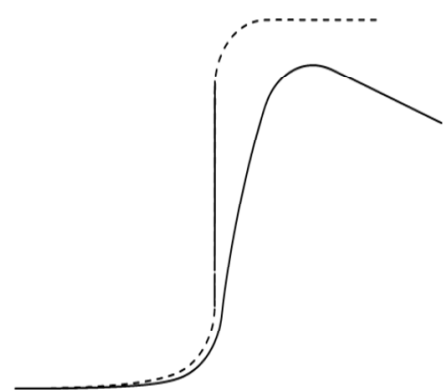

(a)

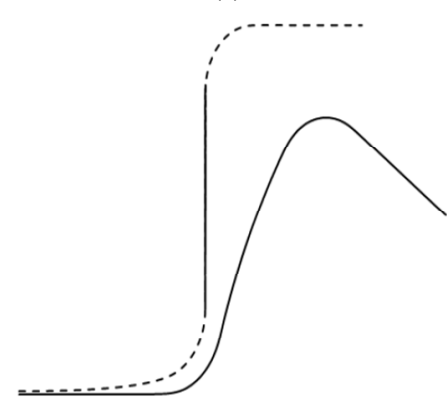

(d)

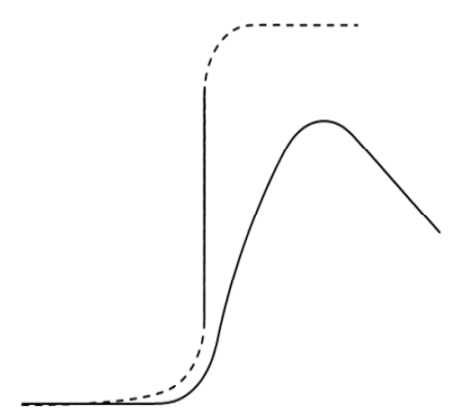

(g)

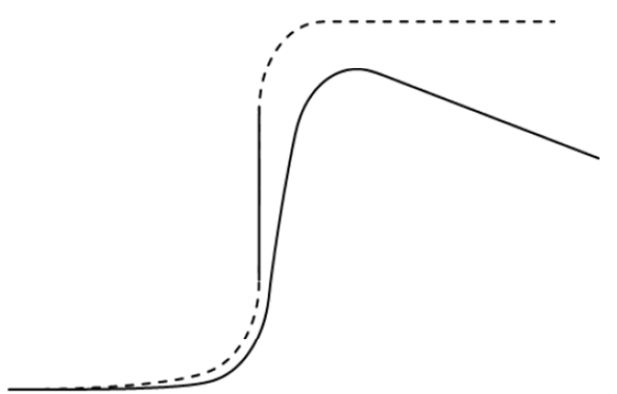

(b)

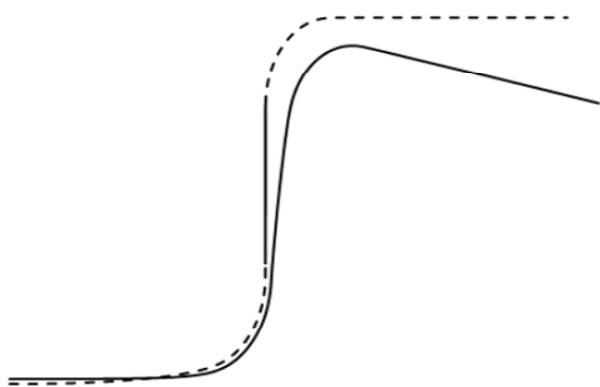

(e)

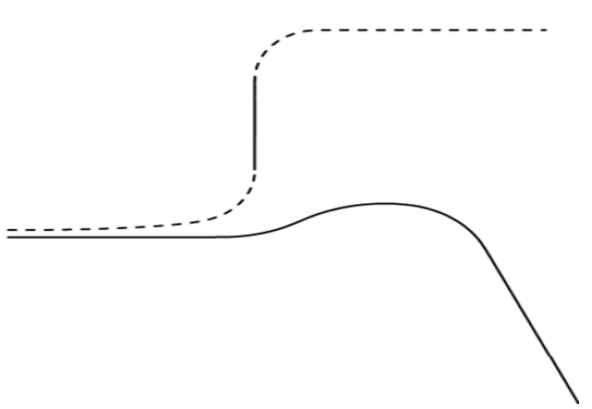

(h)

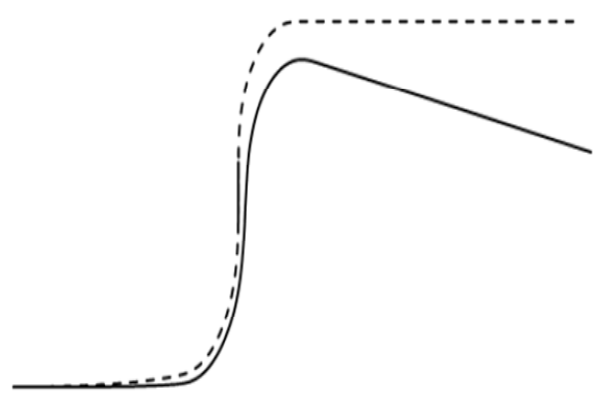

(c)

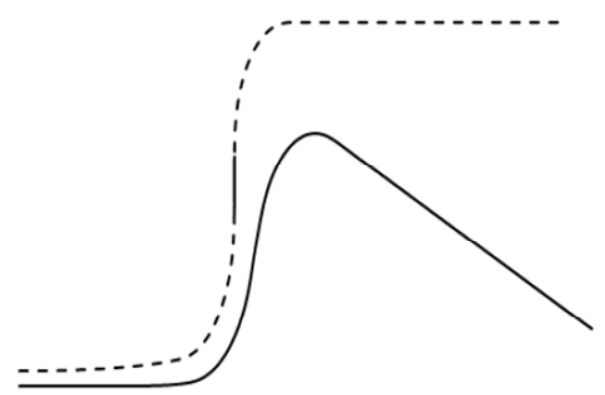

(f)

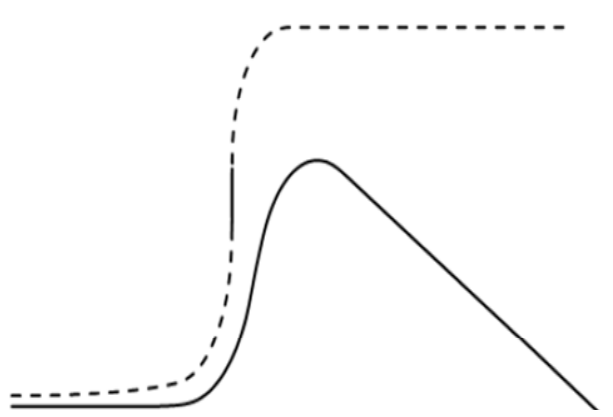

(i)

Figure 11. Spring-back for nine simulations for $L_{9}$ orthogonal array by Taguchi method. 
Table 4. Signal-to-noise ratio for nine conditions.

\begin{tabular}{ccc}
\hline Expt. No. & Predicted Spring-back $(\theta)$ & $\eta=-10 \log \left(y_{i}^{2}\right)$ \\
\hline 1 & 20.82 & -26.37 \\
2 & 15.76 & -23.95 \\
3 & 8.12 & -18.2 \\
4 & 34.00 & -30.63 \\
5 & 10.31 & -20.26 \\
6 & 17.89 & -25.05 \\
7 & 37.54 & -31.49 \\
8 & 65.89 & -36.38 \\
9 & 21.84 & -26.78 \\
& Total & -239.11 \\
& Overall mean & -26.357 \\
\hline
\end{tabular}

In Table $5,{ }^{*}$ value have been used to calculate the pooled error. The magnitude of variance ratio gives a measure of the relative contribution of a factor towards the required minimum pressure, or the sensitivity of the required pressure for a particular factor. A value of variance ratio larger than four indicates the effect of a factor to the quality characteristic is strong, whereas a value less than one is the indicative of negligible effect. Therefore, the spring-back is highly sensitive to the E-value before loading " $E_{B D}$ " and less sensitive to material strain hardening value " $n$ ".

Table 6 shows the average contribution of each factor which when varied at each level and Figure 12 shows the graphical plot of this effect. From this it is observed that the E-value before loading is the most influencing factor on spring-back. However the contribution of punch displacement and material strength coefficient is also much more considerable. The contribution of E-value before loading is coming $47 \%$ whereas the contribution of punch displacement and material strength coefficient is almost equal i.e. $22 \%$.

From the above sensitivity analysis the importance of E-value before loading, material strength coefficient, material strain hardening and the maximum plastic strain attained in the channel has been understood and the consideration of these parameters should take in account while determining the spring-back angle. Thus the Equation (4) is modified by trial and error method understanding and given in Equation (7) for single material and Equation (8) for $\mathrm{m}$ number of materials in the composite channel.

$$
\begin{gathered}
\theta=5\left(\frac{K \varepsilon^{n}}{E_{B D}}\right) \\
\theta=5\left(\frac{K_{1} \varepsilon_{1}^{n_{1}}}{E_{B D_{1}}}+\frac{K_{2} \varepsilon_{2}^{n_{2}}}{E_{B D_{2}}}+\cdots+\frac{K_{m} \varepsilon_{m}^{n_{m}}}{E_{B D_{m}}}\right)
\end{gathered}
$$

Table 5. ANOVA for minimum spring-back in channel forming.

\begin{tabular}{cccccc}
\hline Factors & $\begin{array}{c}\text { Degree } \\
\text { of freedom }\end{array}$ & $\begin{array}{c}\text { Sum } \\
\text { of squares }\end{array}$ & $\begin{array}{c}\text { Mean } \\
\text { square }\left(V_{x}\right)\end{array}$ & \multicolumn{2}{c}{ Variance ratio Percentage } \\
$\left(\mathrm{F}=V_{x} / V_{e}\right)$ & effect \\
\hline$E_{B D}$ & 2 & 120.90 & 60.45 & 5.15 & $47.20 \%$ \\
$\delta$ & 2 & 57.30 & 28.65 & 2.44 & $22.36 \%$ \\
$K$ & 2 & 54.5 & 27.25 & 2.32 & $21.26 \%$ \\
$n$ & 2 & $23.48^{*}$ & 11.74 & 1 & $9.16 \%$ \\
$\begin{array}{c}\text { Total } \\
\text { Pooled } \\
\text { error }\end{array}$ & 8 & 256.18 & -- & -- & -- \\
\hline & 2 & 23.48 & 11.74 & & \\
\hline
\end{tabular}

Table 6. Effect at different levels.

\begin{tabular}{cccc}
\hline Factors & Level 1 & Level 2 & Level 3 \\
\hline$E_{B D}$ & $\mathbf{- 2 2 . 8 4}$ & -25.31 & -31.55 \\
$\delta$ & -29.5 & -26.83 & $\mathbf{- 2 3 . 3 4}$ \\
$K$ & -29.26 & -27.12 & $-\mathbf{2 3 . 3 1}$ \\
$n$ & $-\mathbf{2 4 . 4 7}$ & -26.83 & -28.40 \\
\hline
\end{tabular}

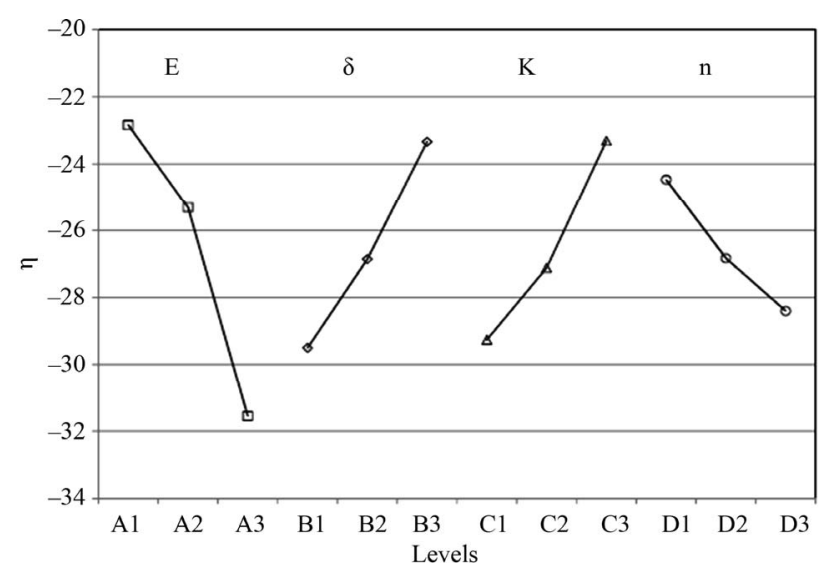

Figure 12. Control factor effect at different levels.

\subsection{Different Elasticity Same Strength Composite Channel}

To understand the composite behavior of E-value change after unloading, the channel is divided into two sections similarly as mentioned in the longitudinal tension test. Each top and bottom layer was given the same hardening behavior but different starting E-value. Thus four simulations were performed for set of starting E-value 210-200, 210-150, 210-100 and 210-50. Resultant E-value of the composite was calculated according to the parallel law [32]. These would be the cases where the composite materials were generated by joining the two strip materials e.g. Steel-Aluminum or Steel-Copper etc. The assumption taken while simulating these channels was that the two strips were perfectly joined together without and interface defect. The spring-back for all four simulations 
is shown in Figure $\mathbf{1 3}$ and the maximum plastic strain values for each case are tabulated in Table 7 . The predicted spring-back angle for all four simulations are tabulated in Table 7 and compared with the calculated value from Equation 8. The calculated value from the proposed equation gave the good agreement with the predicted value. Thus it is noted that the proposed equation obtain from the single starting E-value analysis can be applied for the composite of different starting E-values for comparable results. Similarly the E-value after unloading is calculated from equations proposed from the longitudinal tension test and from channel forming. The both values are in good co-relation (Table 8).

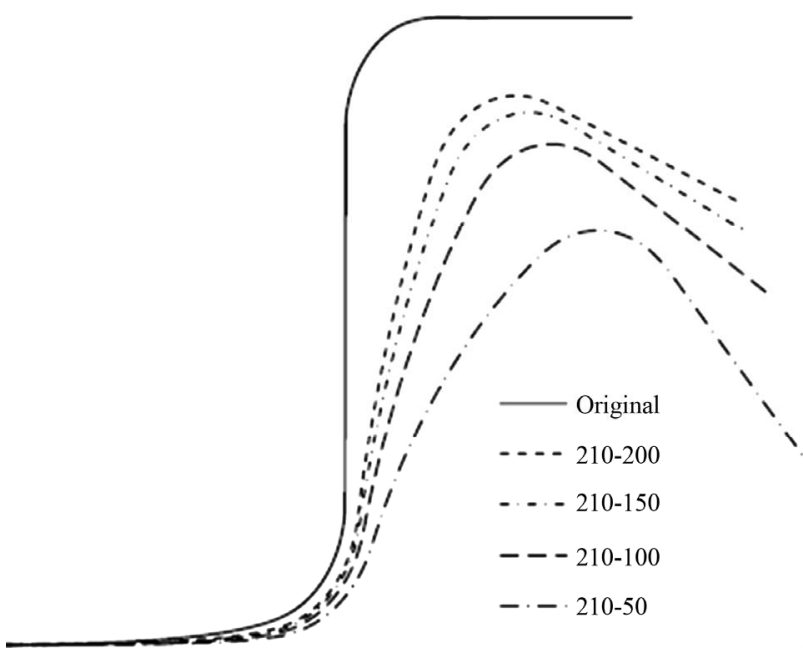

Figure 13. Spring-back for the combination of E-value with same strength level.

Table 7. Prediction and calculation of spring-back angle for different E-value with same strength level.

\begin{tabular}{cccc}
\hline $\begin{array}{c}\text { Combina- } \\
\text { tions }\end{array}$ & $\begin{array}{c}\text { Maximum } \\
\text { Strain }\end{array}$ & $\theta_{\text {Prediction }}$ & $\theta=5\left(\frac{\theta_{\text {Mathematical }}}{E_{B D_{1}}}+\frac{K_{2} \varepsilon_{2}^{n_{2}}}{E_{B D_{2}}}\right)$ \\
\hline $210-200$ & 0.1053 & 21.92 & 21.79 \\
$210-150$ & 0.1021 & 25.34 & 25.63 \\
$210-100$ & 0.0973 & 31.54 & 28.25 \\
$210-50$ & 0.0845 & 47.07 & 52.18 \\
\hline
\end{tabular}

\subsection{Same Elasticity Different Strength Composite Channel}

The behavior of the composite material with different strength level and same starting E-value was understand by performing the longitudinal tension test and further with the channel forming for spring-back. In this section the channel was assumed as a composite material which was self generated due to the increase in temperature on punch or die side during stamping. Due to increase in temperature the material gets soften and thus difference in temperature on punch and die side generates the composite strip. This concept probably occurs in stamping the advanced high strength steel where friction with the tooling is of more importance. Figure 14 shows the predicted E-value after unloading at different plastic strain level for single material; composite material with different starting E-value but same strength level and composite material with same starting E-value but different strength level. It is found that the prediction for single material and composite material with same starting E-value but different strength have same prediction where as there is no comparison for composite material with different starting E-value but same strength. From this it is worth to say that strength level does not matter in case longitudinal test and is completely influence of the starting E-value.

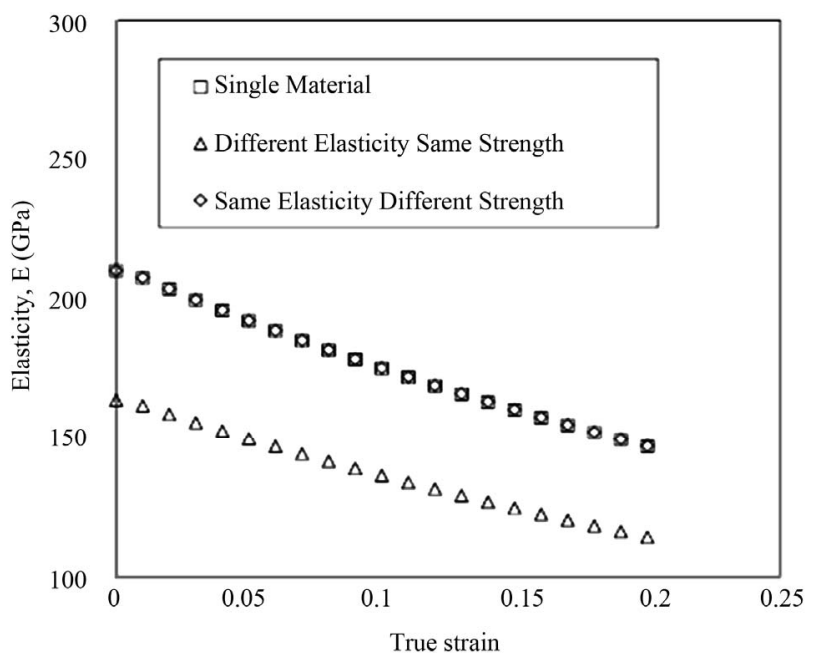

Figure 14. E-value after unloading at different plastic strain.

Table 8. Prediction and calculation of E-value after unloading with same strength level.

\begin{tabular}{ccccc}
\hline \multirow{2}{*}{ Combinations } & $\begin{array}{c}\text { Maximum } \\
\text { Strain }\end{array}$ & $\theta_{\text {Mathematical }}$ & $\theta=5\left(\frac{K_{1} \varepsilon_{1}^{n_{1}}}{E_{B D_{1}}}+\frac{K_{2} \varepsilon_{2}^{n_{2}}}{E_{B D_{2}}}\right)$ & $\begin{array}{c}\mathrm{E}_{\text {Mathematical }} \\
E_{A D}=1.2 \cdot E_{B D} \cdot \theta^{-\varepsilon}\end{array}$ \\
\hline $210-200$ & 0.1053 & 21.79 & 178 & $\begin{array}{c}\mathrm{E}_{\text {Mathematical }} \\
E_{A D}=E_{B D}-1.5 E_{B D} \cdot \varepsilon\end{array}$ \\
$210-150$ & 0.1021 & 25.63 & 155 & 172 \\
$210-100$ & 0.0973 & 28.25 & 134 & 152 \\
$210-50$ & 0.0845 & 52.18 & 111 & 132 \\
\hline
\end{tabular}


To deeply understand the spring-back the four combinations of simulation for channel forming were performed i.e. single "Soft" material, composite "Hard-Soft" material, composite "Soft-Hard" material and single "Hard" material. In two cases the channel was considered as only "Soft" material and only "Hard" material. This implies that there was no increase in temperature during stamping. In other two cases the channel was considered as composite material. In these cases the assumption taken that the increase in temperature during stamping on the punch and the die side was different and thus makes the material soft on one side than the other. In one of these two cases it was assumed that the increase in temperature was higher on the die side and thus the material named as "Hard-Soft" material. Similarly in the second case it was assumed that the increase in temperature was higher on the punch side and thus the material named as "Soft-Hard" material. All materials were assumed to have same starting E-value of $210 \mathrm{GPa}$. It is found that the predicted profile for single Soft material and composite of Hard-Soft material are unexpectedly similar (Figure 15). Whereas the prediction for the single Hard material and composite of Soft-Hard material are not matching with the single soft material spring-back profile which was expected.

The plastic strain achieved in the channel before spring back is predicted for the single soft material and the composite Hard-Soft material (Figure 16). It is observed that the plastic strain achieved at $\sim 35 \mathrm{~mm}$ along the channel (where the bottom bending occurs in the blank) is higher for composite Hard-Soft material than the single Soft material. This follows the lower E-value after unloading in composite Hard-Soft material and expected to get higher spring-back. Similarly the strain achieved at the section $\sim 70 \mathrm{~mm}$ along the channel (i.e. top bending section) are same for both single Soft material and composite Hard-Soft material and expected to get similar springback. But both expectations were wrong. This may be related to the different bending mechanism at both top and bottom corner which is discussed in next section. The predicted strain and the calculated E-value are plotted for single Hard material and composite Soft-Hard material shown in Figures 17 and 18. The maximum strain achieved in all four cases and the corresponding predicted and calculated spring-back angle and the E-value after unloading are tabulated in Tables $\mathbf{9}$ and 10. It is noted that the proposed equation can be used to approximately predict the E-value after unloading and can be use as the helpful tool to design the die, punch and process.

\subsection{Stress Distribution at Corners}

In Figure 19 the channel with two section cuts i.e. Section I and Section II are shown. In Section I the channel bent suddenly once the forming process starts whereas in Section II the channel bend at the end of the forming. In

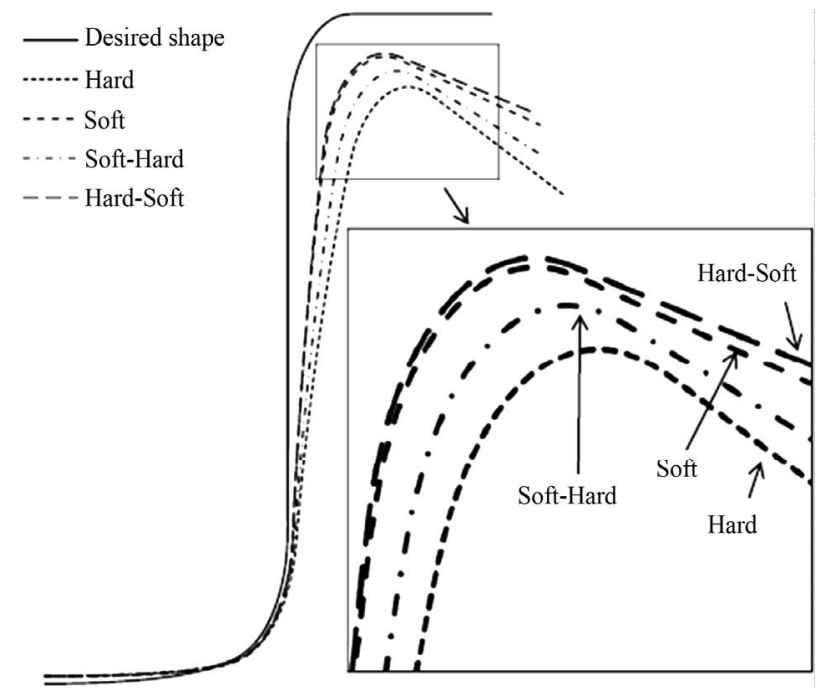

Figure 15. Spring-back for the combination of strength level with same E-value.

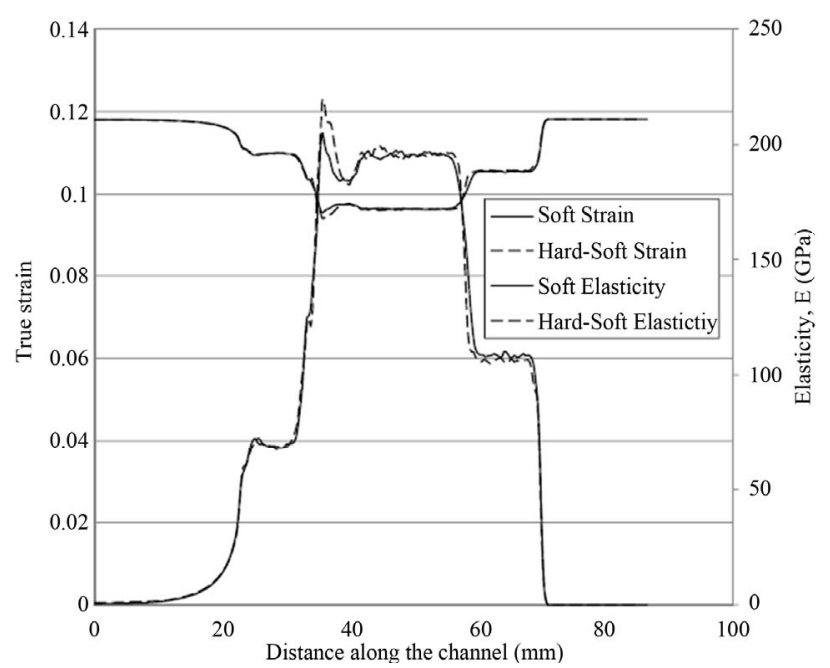

Figure 16. True plastic strain and E-value after unloading along the channel for single Soft metal and the composite Hard-Soft metal.

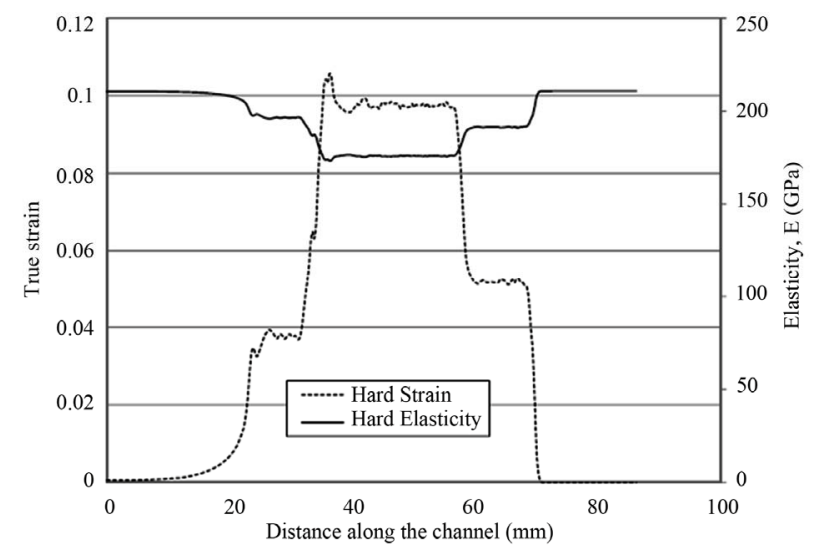

Figure 17. True plastic strain and E-value after unloading along the channel for single Hard metal. 


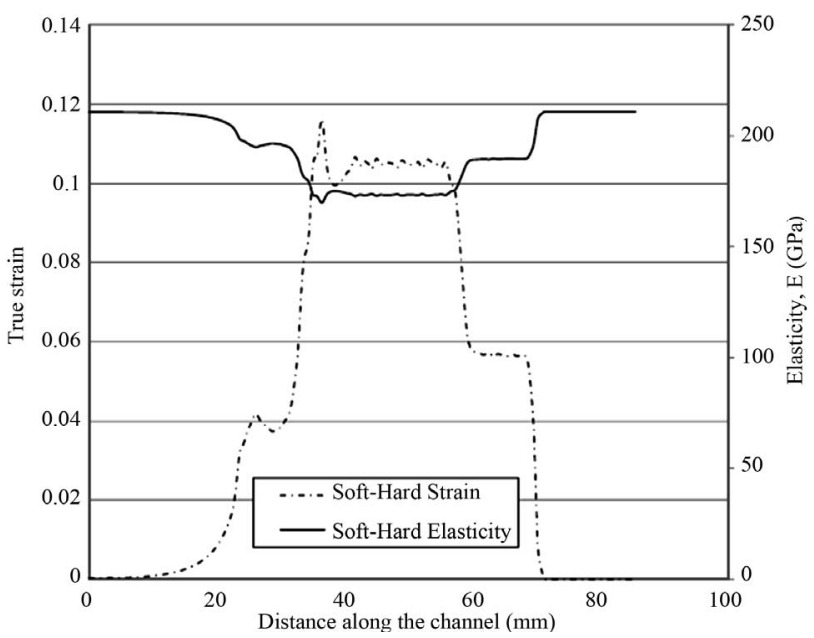

Figure 18. True plastic strain and E-value after unloading along the channel for the composite Soft-Hard metal. between the two sections the channel slides continuously and gives the effect at the end of forming as the curl. In Section I, the stress levels in both tension and compression for the single Soft material as well as the composite Hard-Soft material are almost same (Figure 20) and thus the spring-back is similar at bottom corner. Whereas the stress-levels are different in single Hard material and composite Soft-Hard material. The compression bending of the hard material was supported by the tension of the soft material at bottom corner for the composite Hard-Soft material and thus helped in reduction of the spring-back. In Section II, the tension as well as the compressive stress levels for single Soft material is lower than the composite Hard-Soft material and this is the possible reason to get the lower spring-back in the later case. The stress levels for the remaining cases are completely different and thus have different spring-back (Figure 21).

Table 9. Prediction and calculation of spring-back angle for different strength level with same E-value.

\begin{tabular}{cccc}
\hline Combinations & Maximum Strain & $\theta_{\text {Prediction }}$ & $\theta_{\text {Mathematical }} \theta=5\left(\frac{K_{1} \varepsilon_{1}^{n_{1}}}{E_{B D_{1}}}+\frac{K_{2} \varepsilon_{2}^{n_{2}}}{E_{B D_{2}}}\right)$ \\
\hline Soft & 0.1148 & 13.53 & 11.07 \\
Hard & 0.1057 & 21.38 & 21.30 \\
Soft-Hard & 0.1161 & 18.03 & 15.09 \\
Hard-Soft & 0.1228 & 12.20 & 15.62 \\
\hline
\end{tabular}

Table 10. Prediction and calculation of E-value after unloading with different strength level.

\begin{tabular}{|c|c|c|c|c|c|c|c|}
\hline Combinations & Maximum Strain & $\theta_{\text {Mathematical }}$ & $\theta=5\left(\frac{K_{1} \varepsilon_{1}^{n_{1}}}{E_{B D_{1}}}+\frac{K_{2} \varepsilon_{2}^{n_{2}}}{E_{B D_{2}}}\right)$ & $E_{\text {Mathematical }}$ & $E_{A D}=1.2 \cdot E_{B D} \cdot \theta^{-\varepsilon}$ & $E_{\text {Mathematical }}$ & $E_{A D}=E_{B D}-1.5 E_{B D} \cdot \varepsilon$ \\
\hline Soft & 0.1148 & & 11.07 & & 191 & & 173 \\
\hline Hard & 0.1057 & & 21.30 & & 182 & & 176 \\
\hline Soft-Hard & 0.1161 & & 15.09 & & 184 & & 173 \\
\hline Hard-Soft & 0.1228 & & 15.62 & & 180 & & 171 \\
\hline
\end{tabular}

\section{Conclusions}

The E-value after unloading was performed with the simple longitudinal tension test and the channel forming test. It was found that the E-value after unloading decreases with the increase in plastic strain. It was also observed that the E-value after unloading in longitudinal tension test depends on the starting E-value and has no effect of strength level of the material. Further the spring-back prediction was studied with the channel forming model. Here the equation was proposed to determine the E-value after unloading which depends on the starting E-value, spring-back angle and the maximum strain value achieved in the channel. The proposed equation for E-value with both longitudinal tension test and channel forming model gave the similar prediction and can be used as the tool to

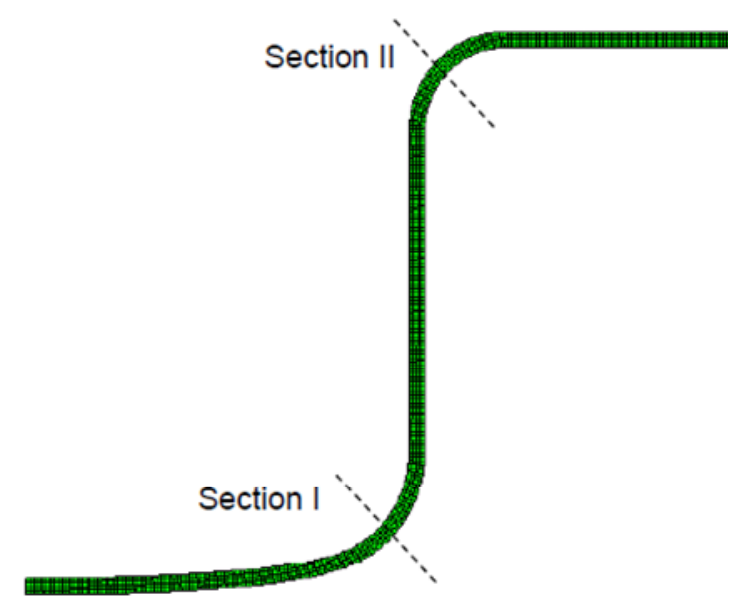

Figure 19. Two sections of channel for stress analysis. 


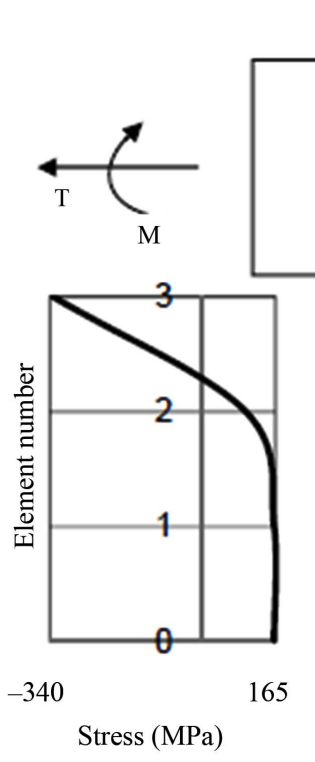

(a)

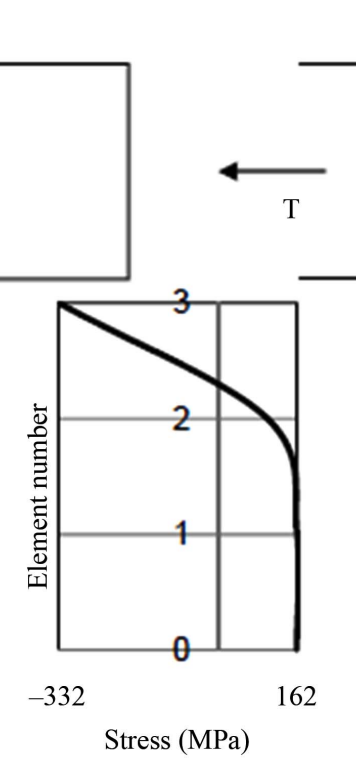

(b)

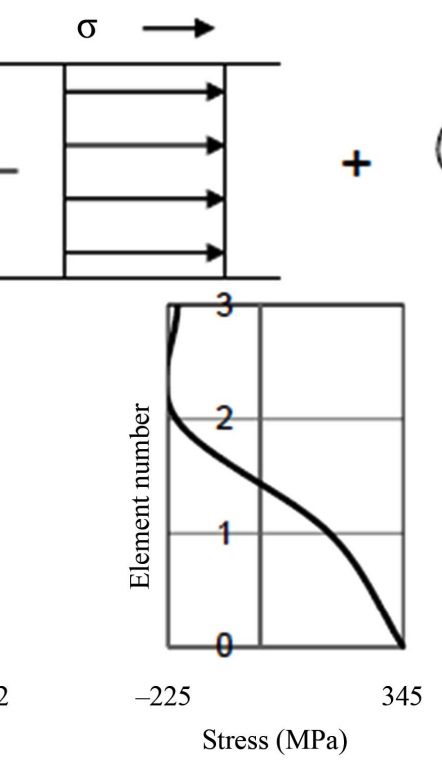

(c)

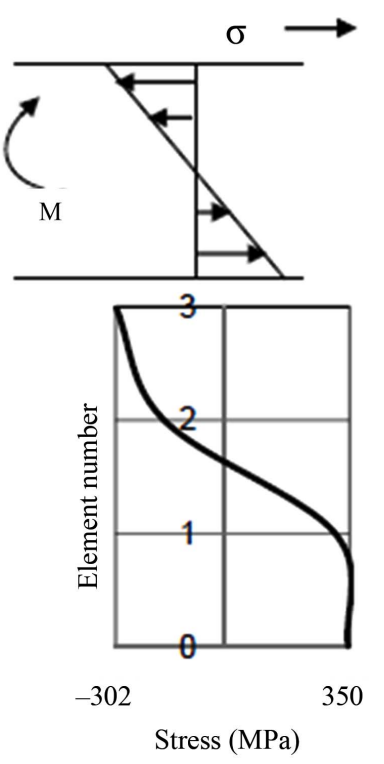

(d)

Figure 20. Stress level achieved at Section I by compression and tension loading for (a) Soft, (b) Hard-Soft, (c) Soft-Hard, (d) Hard metal.

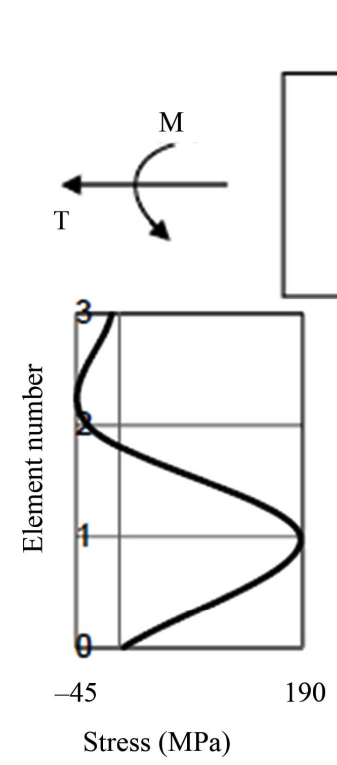

(a)

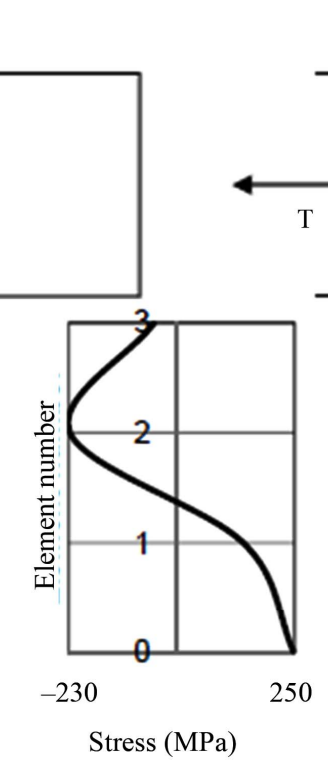

(b)

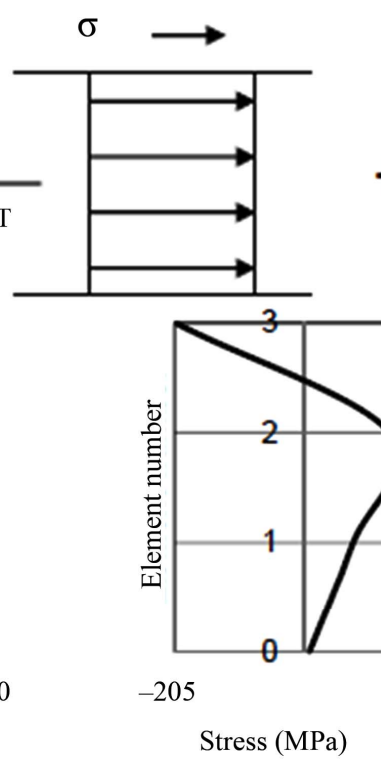

(c)

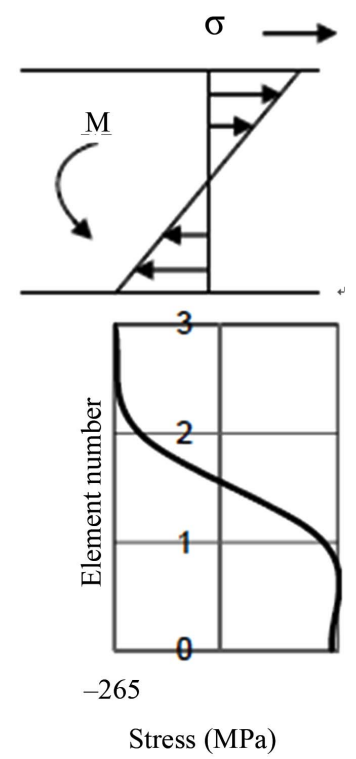

(d)

Figure 21. Stress level achieved at Section II by compression and tension loading for (a) Soft, (b) Hard-Soft, (c) Soft-Hard, (d) Hard metal.

design the die, punch and the process to reduce the spring-back. In addition the spring-back prediction was studied for the composite material. The interesting fact was observed that the stress level in both tension and compression are same in both single Soft material and composite Hard-Soft material and thus gave the similar amount of spring-back prediction. Therefore this can be use as a helpful tool to design the new material for the elimination of spring-back. This indicated that the composite material with Hard layer touches to punch and soft layer touches to the die will give the same spring-back for the single softer material.

\section{Acknowledgements}

The author would like to extend his gratitude to Professor Peter D. Hodgson and Professor Brad L. Kinsey for support and Deakin University and University of New Hampshire for providing the facility to carry out this research work. 


\section{REFERENCES}

[1] R. Wagoner and M. Li, "Simulation of Springback: ThroughThickness Integration," International Journal of Plasticity, Vol. 23, No. 3, 2007, pp. 345-360. doi:10.1016/j.ijplas.2006.04.005

[2] N. Narasimhan and M. Lovell, "Predicting Springback in Sheet Metal Forming: An Explicit to Implicit Sequential Solution Procedure," Finite Elements in Analysis and Design, Vol. 33, No. 1, 1999, pp. 29-42. doi:10.1016/S0168-874X(99)00009-8

[3] H. S. Cheng, J. Cao and Z. Xia, "An Accelerated Springback Compensation Method," International Journal of Mechanical Sciences, Vol. 49, No. 3, 2007, pp. 267-279. doi:10.1016/i.ijmecsci.2006.09.008

[4] K. Li, W. Carden and R. Wagoner, "Simulation of Springback," International Journal of Mechanical Sciences, Vol. 44, No. 1, 2002, pp. 103-122. doi:10.1016/S0020-7403(01)00083-2

[5] J. Gau and G. Kinzel, "A New Model for Springback Prediction in which the Bauschinger Effect Is Considered," International Journal of Mechanical Sciences, Vol. 43, No. 8, 2001, pp. 1813-1832. doi:10.1016/S0020-7403(01)00012-1

[6] S. Lee and Y. Kim, "A Study on the Springback in the Sheet Metal Flange Drawing," Journal of Materials Processing Technology, Vol. 187-188, 2007, pp. 89-93. doi:10.1016/j.jmatprotec.2006.11.079

[7] K. Mori, K. Akita and Y. Abe, "Springback Behaviour in Bending of Ultra-High-Strength Steel Sheets Using CNC Servo Press," International Journal of Machine Tools and Manufacture, Vol. 47, No. 2, 2007, pp. 321-325. doi:10.1016/j.ijmachtools.2006.03.013

[8] T. Hilditch, J. Speer and D. Matlock, "Influence of Low-Strain Deformation Characteristics of High Strength Sheet Steel on Curl and Springback in Bend-Under-Tension Tests," Journal of Materials Processing Technology, Vol. 182, No. 1-3, 2007, pp. 84-94. doi:10.1016/j.jmatprotec.2006.06.020

[9] M. Oliveira, J. L. Alves, B. M. Chaparro and L. F. Menezes, "Study on the Influence of Work-Hardening Modeling in Springback Prediction," International Journal of Plasticity, Vol. 23, No. 3, 2007, pp. 516-543. doi:10.1016/j.ijplas.2006.07.003

[10] H. Haddadi, S. Bouvier, M. Banu, C. Maier and C. Teodosiu, "Towards an Accurate Description of the Anisotropic Behaviour of Sheet Metals under Large Plastic Deformations: Modelling, Numerical Analysis and Identification," International Journal of Plasticity, Vol. 22, No. 12, 2006, pp. 2226-2271. doi:10.1016/j.ijplas.2006.03.010

[11] B. M. Chaparro, M. C. Oliveira, J. L. Alves and L. F. Menezes, "Work Hardening Models and the Numerical Simulation of the Deep Drawing Process," Material Science Forum, Vol. 455-456, 2004, pp. 717-722. doi:10.4028/www.scientific.net/MSF.455-456.717

[12] S. Bouvier, J. L. Alves, M. C. Oliveira and L. F. Menezes, "Modelling of Anisotropic Work-Hardening Behaviour of Metallic Materials Subjected to Strain-Path Changes,"
Computational Materials Science, Vol. 32, No. 3-4, 2005, pp. 301-315. doi:10.1016/j.commatsci.2004.09.038

[13] Z. Dongjuan, C. Zhenshan, R. Xueyu and L. Yuqiang, "Sheet Springback Prediction Based on Non-Linear Combined Hardening Rule and Barlat89's Yielding Function," Computational Materials Science, Vol. 38, No. 2, 2006, pp. 256-262. doi:10.1016/j.commatsci.2006.02.007

[14] J. Alves, M. Oliveira and L. Menezes, "Drawbeads: To Be or Not To Be," In: J. Cao, et al., Editors, Numisheet '05 6th International Conference and Workshop on Numerical Simulation of $3 D$ Sheet Forming Processes: On the Cutting Edge of Technology, Part A, The American Institute of Physics 778, NUMISHEET 2005 Conference, 15-19 August 2005, Detroit, Michigan, pp. 655660.

[15] A. Andersson and S. Holmberg, "Simulation and Verification of Different Parameters Effect on Springback Results," NUMISHEET, Jeju Island, Korea, 21-25 October 2002, pp. 201-206.

[16] N. Yamamura, T. Kuwabara and A. Makinouchi, "Springback Simulations for Stretch-Bending and Drawbending Processes Using the Static Explicit FEM Code, with an Algorithm for Canceling Non-Equilibrated Forces," NUMISHEET, Jeju Island, Korea, 21-25 October 2002, pp. 25-30.

[17] L. Bjorkhaug and T. Welo, "Local Calibration of Aluminum Profiles in Rotary Stretch Bending-Anisotropy Effects," Materials Processes and Design: Modeling, Simulation and Applications, NUMIFORM, Columbus, $\mathrm{OH}$, USA, 2004, pp. 749-754.

[18] H. Yao, S. D. Liu, C. Du and Y. Hu, "Techniques to Improve Springback Prediction Accuracy Using Dynamic Explicit FEA Codes," SAE TRANSACTIONS, Vol. 111, 2002, pp. 100-106.

[19] V. Nguyen, Z. Chen and P. Thomson, "Prediction of Spring-Back in Anisotropic Sheet Metals," Proceedings of the Institution of Mechanical Engineers, Part C: Journal of Mechanical Engineering Science, Vol. 218, No. 6, 2004, pp. 651-661.

[20] W. Xu, C. H. Ma, C. H. Li and W. J. Feng, "Sensitive Factors in Springback Simulation for Sheet Metal Forming," Journal of Materials Processing Technology, Vol. 151, No. 1-3, 2004, pp. 217-222. doi:10.1016/j.jmatprotec.2004.04.044

[21] R. Wagoner, L. Geng and K. Li, "Simulation of Springback with the Draw/Bend Test," IPMM '99: The Second International Conference on Intelligent Processing and Manufacturing of Materials, Honolulu, HI, USA, 10-15 July 1999, pp. 91-104.

[22] C. Hinsinger, V. Zwilling and O. Hudin, "Experimental and Numerical Approaches of Springback of High-Performance Steels Drawn With U-Shaped Tools and An Industrial Side Member Tool," SAE TRANSACTIONS, Vol. 111, 2002, pp. 2054-2068.

[23] S. Chatti, "Effect of the Elasticity Formulation in Finite Strain on Springback Prediction," Computers \& Structures, Vol. 88, No. 11-12, 2010, pp. 796-805. doi:10.1016/j.compstruc.2010.03.005 
[24] A. Gandhi and H. Raval, "Analytical Modeling of Top Roller Position for Multiple Pass (3-Roller) Cylindrical Forming of Plates," International Mechanical Engineering Congress and Exposition, Chicago, IL, USA, 5-10 November 2006, pp. 107-116.

[25] A. Gandhi and H. Raval, "Analytical and Empirical Modeling of Top Roller Position for Three-Roller Cylindrical Bending of Plates and Its Experimental Verification," Journal of Materials Processing Technology, Vol. 197, No. 1-3, 2008, pp. 268-278. doi:10.1016/j.jmatprotec.2007.06.033

[26] H. Yu, "Variation of Elastic Modulus during Plastic Deformation and Its Influence on Springback," Materials \& Design, Vol. 30, No. 3, 2009, pp. 846-850. doi:10.1016/j.matdes.2008.05.064

[27] F. Morestin and M. Boivin, "On the Necessity of Taking into Account the Variation in the Young Modulus with Plastic Strain in Elastic-Plastic Software," Nuclear Engineering and Design, Vol. 162, No. 1, 1996, pp. 107-116. doi:10.1016/0029-5493(95)01123-4

\section{Nomenclature}

E-value-Material Young's modulus YS-Material Yield Strength

$\boldsymbol{\sigma}$-True stress

$\boldsymbol{\varepsilon}$-True plastic strain (In case of subscript $1,2 \ldots \ldots \mathrm{m}$ indicates for material $1,2 \ldots \ldots \mathrm{m}$ in composite material)

$\boldsymbol{K}$-Material strength coefficient (In case of subscript $1,2 \ldots \ldots \mathrm{m}$ indicates for material $1,2 \ldots \ldots \mathrm{m}$ in composite material)

$\boldsymbol{n}$-Material strain hardening exponent (In case of subscript $1,2 \ldots \ldots \mathrm{m}$ indicates for material $1,2 \ldots \ldots \mathrm{m}$ in
[28] M. Yang, Y. Akiyama and T. Sasaki, "Evaluation of Change in Material Properties Due to Plastic Deformation," Journal of Materials Processing Technology, Vol. 151, No. 1-3, 2004, pp. 232-236. doi:10.1016/j.jmatprotec.2004.04.114

[29] D. Fei and P. Hodgson, "Experimental and Numerical Studies of Springback in Air V-Bending Process for Cold Rolled TRIP Steels," Nuclear Engineering and Design, Vol. 236, No. 18, 2006, pp. 1847-1851. doi:10.1016/j.nucengdes.2006.01.016

[30] F. Yoshida, T. Uemori and K. Fujiwara, "Elastic-Plastic Behavior of Steel Sheets under In-Plane Cyclic Tension-Compression at Large Strain," International Journal of Plasticity, Vol. 18, 2002, pp. 633-659. doi:10.1016/S0749-6419(01)00049-3

[31] M. Phadke, "Quality Engineering Using Robust Design," Prentice Hall, Englewood Cliffs, NJ, USA, 1989.

[32] R. Hibbeler, "Mechanics of Materials," 7th Edition, Pearson Education, Cranbury, NJ, USA, 2008.

composite material)

$\boldsymbol{\eta}$-Optimise function for sensitivity analysis

$\boldsymbol{\theta}$-Spring-back angle or Theta

$\boldsymbol{E}_{\boldsymbol{B} \boldsymbol{D}}$-E-value before deformation or before loading or starting E-value (In case of subscript 1,2 ....m indicates for material $1,2 \ldots \ldots \mathrm{m}$ in composite material)

$\boldsymbol{E}_{\boldsymbol{A} \boldsymbol{D}}$-E-value after deformation or after unloading

$\boldsymbol{\delta}$ : Punch displacement in channel forming

Soft-Hard material-The composite material which has the soft layer touches the punch and hard layer touches the die 